\title{
Discourses that Inform the Chilly Climate in Math and Physics
}

\author{
Laura Parson $^{\mathrm{a} 1}$, C. Casey Ozaki ${ }^{\mathrm{b}}$ \\ ${ }^{a}$ Auburn University, USA; ${ }^{b}$ University of North Dakota, USA
}

\begin{abstract}
The purpose of this study was to uncover and describe the institutional classroom practices of STEM education at a Midwest research university (MRU). Using the framework of feminist standpoint theory, this study explored the everyday experiences of undergraduate women in math and physics to provide a unique perspective on the STEM education teaching and learning environment. In analysis of student interviews, faculty interviews, classroom observations, and instructional documents, we found that the difficult and intimidating aspects of the teaching and learning environment that created challenges for women participants were guided by STEM discourses of individualism, competition, and difficulty. These findings indicate that recent efforts to reduce the "chilly" climate have been unsuccessful because the discourses that motivate the chilly climate have not changed. Recommendations include revising the STEM institution to one that is inclusive for non-man students by identifying and revising the teaching and learning practices motivated by the discourses of competition, individualism, and difficulty.
\end{abstract}

Keywords: STEM education, Institutional Ethnography, Higher Education, Qualitative Research, Chilly Climate

\section{Institutional Discourses that Inform the Chilly Climate in Math and Physics}

For many undergraduate women in Science, Technology, Engineering and Math (STEM), the classroom environment is a setting that is man-normed, highly impersonal, and individualistic (Morganson, Jones, \& Major, 2010; Vogt, Hocevar, \& Hagedorn, 2007). Referred to as a "chilly climate," STEM classroom environments are frequently organized as, "competitive, weed-out systems that are hierarchically structured with impersonal professors. These characteristics are traditionally acknowledged as customary, even respectable, teaching practices in traditional research university science, mathematics, and engineering classrooms" (Vogt et al., 2007, p. 339).

While the competitive STEM academic environment is often accepted and even promoted at traditional research universities (Vogt et al., 2007), this chilly climate can lead women to feel that they do not belong in STEM fields. For many women at the undergraduate and graduate level, the competitive STEM environment is discouraging instead of motivating; research suggests that women in STEM feel like they do not have the social and emotional support they need to be successful or they feel that they are not academically strong enough to be successful in the STEM industry (Herzig, 2010; Sartorius, 2010; Shapiro \& Sax, 2011). The classroom climate and lack of support creates a disconnect that restricts undergraduate women's enrollment and persistence in STEM fields and may prevent them from feeling that they belong in STEM fields (Sartorius, 2010). This disconnect may have a negative effect on women student's persistence to graduation. For example, Gayles and Ampaw (2014) found that campus climate and environmental factors negatively affected women's persistence in STEM majors.

\footnotetext{
${ }^{1}$ Corresponding author. Department of Educational Foundations, Leadership, \& Technology, Auburn University, 4036 Haley Center, Auburn, AL 36849 E-mail: ljp@auburn.edu
}

Parson, L., \& Ozaki, C. C. (2017). Discourses that Inform the Chilly Climate in Math and Physics. Journal of Research in STEM Education, 3(1/2), 34-47 
Guided by the discourses of individualism and competition, STEM teaching and learning practices that contribute to a chilly climate are weed-out courses, courses that grade on a curve, reliance on lecture as a teaching method, and comprehensive exams (Mervis, 2011; Morganson et al., 2010; Shapiro \& Sax, 2011). For example, weed out courses are introductory STEM courses designed to be so difficult they push out students perceived to be unprepared for (or identify those perceived to be unable to be successful in) difficult upper division courses (Mervis, 2011). This practice can create a competitive environment that is negative for women and minorities: "women do not find competition a meaningful way to receive feedback and may even find it to be offensive" (Shapiro \& Sax, 2011, p. 8). The competitive nature of STEM courses is reinforced in large, lecture-based classroom and instructional practices that promote competition between students to be at the top of the class (Shapiro \& Sax, 2011). Finally, competition in STEM classes is often reinforced through grading policies and a focus on individual achievement, "faculty in the sciences are more likely to grade on a curve, which promotes competition among students ... [and] discourages collaborative work, instead reinforcing the notion that individuals should take responsibility only for their own learning" (Shapiro \& Sax, 2011, p. 8). The chilly climate reinforces societal suggestions that women do not belong in STEM fields. The practices that characterize the chilly climate are symptomatic of the institutional discourses, practices, policies, and procedures that inform and guide those practices.

\section{Study Purpose}

Calls for research at the institutional level have increased in order to re-make the STEM classroom into one in which women are welcome and comfortable. To challenge the existing social and scientific systems, this study uncovered and described the institutional practices of STEM education at a Midwest research university (hereafter referred to as MRU) from the standpoint of undergraduate women. This article reports on a portion of a larger institutional ethnography of STEM education at MRU; in this manuscript, we explored data collected on classroom and department-level teaching and learning practices (See Parson \& Ozaki, 2017; Parson, 2018). Specifically, we asked what STEM teaching and learning practices and processes characterized the organization of the day-to-day work of being a math and physics student and if challenges emerged for undergraduate women as a result of those organizational processes.

Standpoint theory provides the theoretical foundation of an institutional ethnography, beginning data collection with women who are able to describe the practices and procedures that keep them oppressed because those forces directly affect their lived experiences (Smith, 2005). Guided by standpoint theory, we began our inquiry into the STEM in higher education institution by understanding the experiences and perceptions of undergraduate women in math and physics. Their experiences acted as a window to identify the institutional processes and discourses that coordinated their lives. Through the framework of feminist standpoint theory, we sought to shift the standpoint of knowing by recognizing women's ways of knowing as equally valid (Belenky, Clinchy, Goldberger, \& Tarule, 1997; Hesse-Biber \& Nagy, 2014) and asserting that knowledge develops from lived experiences (Harding, 2004; Hesse-Biber \& Nagy, 2014). By exploring the institutional factors that coordinate the chilly classroom climate, this study extends understanding of the chilly climate to provide understanding of the discourses, policies, practices, and procedures that lead to the classroom practices that characterize the chilly climate.

\section{Methods}

Data collection and analysis focused on how the interface between undergraduate women and STEM education was organized as a matter of daily encounters between students and faculty inside and outside of the classroom. This exploration began with in-depth interviews of eight undergraduate women in math and physics and extended, as the institutional processes shaping their experiences were identified, to classroom observations, additional interviews of students and faculty, and analysis of the texts that mediated these processes (e.g., syllabi and student handbooks). Student and faculty interviews provided a majority of the data explored in this portion 
of the larger institutional ethnography guided by the research questions:

1. What STEM teaching and learning practices and processes characterize the organization of everyday work for women math and physics students?

2. Do challenges emerge for women undergraduate students as a result of those organizational processes? If so, how and where do they emerge?

\section{Participants}

In an institutional ethnography, the goal of interviews is not just to reveal subjective states, but to identify how individuals from different parts of an institution are connected. Data from initial data collection guides the next steps of an investigation in order to identify local processes that are similar because they are coordinated by the same (or similar) institutional practices (Campbell \& Gregor, 2004). In order to identify these translocal processes, procedures, and discourses, participants were chosen from two departments, math and physics, instead of just one (Smith, 2006, loc 327). Undergraduate participants were identified by asking math and physics faculty to ask qualifying participants to contact us if they were interested in participating in the research. Undergraduate participants were four physics majors, three math majors, and one math/ physics double major. In addition to student participants, eight faculty members participated in interviews and classroom observations: four faculty participants from physics and four faculty participants from math. Student and faculty interviews and observations occurred during Fall 2015.

\section{Data Collection}

Smith (2005) outlines institutional ethnographic data collection procedures as beginning with entrylevel data collection, followed by the collection of level two data. In an institutional ethnography, entry-level data informs understanding of the lived experiences of participants (Campbell \& Gregor, 2004). Level two data provides insight into the institutional practices that coordinate level one data, practices that are often invisible to participants (Smith, 2005). In this study, entry-level data, collected in student interviews, identified the components of the teaching and learning environment that were described by participants as challenging. Then, subsequent data collection illuminated the discourses, policy, and practices that coordinated participant's lives, referred to as level two data. Level two data helped us to understand how and why those challenges were coordinated by institutional processes, procedures, and discourses. Level two data was collected through interviews with undergraduate women, classroom observations, faculty interviews, and institutional texts.

Interviews. In-depth interviews were guided by the core question of an institutional ethnography: How do you do what you do? (Campbell \& Gregor, 2004). Laura conducted a total of 21 undergraduate participant interviews. With six of the eight participants, Laura conducted three interviews after receiving informed consent: at the beginning, middle, and end of the Fall 2015 semester. In each interview, Laura asked students to provide rich detail describing their everyday activities, including in-depth descriptions of the different settings as well as of their work and the work of other students, which might include attending class, completing homework, studying with peers, and attending advising sessions. (Campbell \& Gregor, 2004). The interviews were formal and in-depth and lasted between 30-90 minutes.

Laura also conducted shorter formal interviews with math and physics faculty after the first undergraduate interviews were conducted. Those interviews asked about the processes and policies that were identified in the undergraduate interviews and/or observations and provided information about how student work is coordinated at the department, college, and institutional level. Laura conducted a total of five interviews; three with physics faculty and two with mathematics faculty. The interviews lasted between 30-60 minutes and occurred in October 2015. 


\section{Data Analysis}

Following Carspecken's (1996) critical ethnographic coding processes, initial data analysis began immediately after the transcription of interviews. We began with low-level coding, which included structural and descriptive coding (Saldana, 2013) that identified the work that was being done by undergraduate women (Smith, 2005). After the first and second undergraduate interviews, faculty interviews and classroom observations were transcribed and analyzed for low-level codes. After data collection was complete, we began high-level coding of the data by identifying and explicating themes in the teaching and learning practices, policies, and procedures that coordinated participant work (Smith, 2005; 2006). We looked specifically for the discourses, power relationships, language, and practices crafted practices that were either gendered or biased or neutral and normal (Campbell \& Gregor, 2004). Finally, we reorganized codes into categories using code maps and analytic memoing (Saldana, 2013).

\section{Trustworthiness and Ethics}

To ensure the validity of data collection and analysis, we used triangulation, prolonged and persistent engagement, peer debriefing, and audit trails. For example, to seek data, methodological, and theory triangulation, we triangulated findings by comparing data across participants and different data sources (Onwuegbuzie \& Leech, 2007). Additionally, throughout the data collection and analysis process, we revisited the literature to see how findings aligned with the literature and for additional insight and clarification (Creswell, 2013). Finally, we collected rich data through interviews and observations (Creswell, 2013; Maxwell, 2013; Onwuegbuzie \& Leech, 2007) such as the use of repeated interviews of subjects to produce richer and more self-disclosing work.

We sought to collect and analyze data with a primary focus on ethics throughout the study, including data collection, data analysis, and reporting. First, we used in-depth interviews that were guided by the participant to empower women participants by being heard and validated as an authority. Second, our study received ethical approval from the MRU IRB board prior to beginning data collection (Rossman \& Rallis, 2003). We obtained informed consent from all participants and conducted interviews and observations with the goal of ensuring privacy and confidentiality. Finally, we protected the identity of each study participant by using pseudonyms in interview transcripts, observations, and researcher memos and by removing all identifiable information from any published reports, including participant quotes (Creswell, 2013; Rossman \& Rallis, 2003).

\section{Limitations}

First, much of the research on the undergraduate gender gap has focused on the experiences of undergraduate women in Math and Physics fields, and this study builds on that research. However, it is possible that the chilly climate and resultant discomfort reported by participants in this study is not uniquely related to gender but could create a chilly climate for all students, regardless of gender. Because this research was framed from the standpoint of women and this study only explores the experiences of undergraduate women in math and physics, we did not feel comfortable extending our conclusions beyond the parameters of this study.

Second, the literature and a faculty participant suggested that the discomfort expressed by women in STEM could be attributed to experiences in education prior to entering higher education (Sax \& Harper, 2007). As a qualitative exploration, this study did not control for prior academic experiences when choosing participants in order to identify a causational relationship between experiences in higher education and causes for the chilly climate and leaky pipeline. That was not the intent of this study, and we do not intend to communicate broad generalizability. However, it is possible that negative emotions experienced by undergraduate participants were related to their prior experiences in math and physics and not to the environment in higher education. 


\section{Findings}

The lived experiences of undergraduate participants in this study, women majoring in math and physics, provided insight into procedures and pedagogical decisions that led to discomfort in the STEM classroom and program in this study. First, participant descriptions of coursework defined the fields of math and physics as difficult. Second, assessment and grading practices, such as comprehensive exams and grading on a curve, reinforced the discourse of difficulty in STEM for participants. Third, participant interactions with faculty and instructional language formed an intimidating classroom environment. Finally, discourses of individualism and competitiveness were seen throughout the teaching and learning environment and created discomfort for participants.

\section{"Physics is Hard": The Discourse of Difficulty}

An overarching theme that repeated itself in every interview and from every participant was their perception that getting a math or physics degree was hard. Undergraduate participants explained that their coursework was hard because physics and math were, by nature, "really hard" and that courses were tough because the topics students were learning, such as quantum mechanics, abstract algebra, and linear algebra, were complicated and complex. For example, physics major Michelle explained, "They all warned me that it was going to be hard, and it was hard . . like [this] teacher's really hard, he pushes you hard. He used to teach at Princeton. So, he had a very set idea of what homework should be, and it's the most grueling thing ever." Participants' descriptions of demanding coursework and complex subject matter were supported by faculty. Karl, a faculty member in physics, explained how he created physics exams, "I cannot ask quantum physics questions that they would get $95 \%$. Then, my quantum physics class is a joke. Or they are genius. Topic is too hard. Very elaborate thing."

In addition to the challenging nature of math and physics content, coursework was made more difficult through unclear language and expectations. First, math and physics coursework was difficult, because the language used in assignments was unclear, which made figuring out what students were expected to do the first homework hurdle. For example, math major Emma described the coursework:

You go to class and you're sitting in your classroom and your professor starts with his lecture and you're just like, okay, so I kinda understand some of the things that are going on and you just kinda nod your head, okay-oh, okay - and then you get to your assignment and you're just like I have no clue what's going on. Nothing in the lecture has prepared me for this assignment. I don't understand what's going on.

Participants described assignments that required participants to first understand what was being asked before they could work on the problem itself. Unclear language made it difficult for undergraduate participants to understand what a problem required of them. Additionally, homework and exam questions would often apply or extend the material covered in class, in ways that participants found difficult. As a result, participants described two challenges associated with coursework: figuring out what a question was requiring of them and then solving the problem.

Second, assignments that required large amounts of time to complete added to the difficulty of the coursework. Physics major Julie described the work she and her physics peers put into completing one homework assignment for one class:

We worked on it every night and all day Saturday until about 4 oclock when we finally finished it. It's just that there are so many things, and when you go ask, a lot [of] times he [the professor] will say, "Well, it's obvious. Just think about it!" It's frustrating, and we ended up going back through and looking stuff up online and bringing out our partial differential equations books and other books, our linear algebra book, to try to figure out what some of the problems were. 
Coursework is time-consuming because of how hard the problems are and because of the resources students need to identify and search through relevant material that might help them determine how to complete their homework.

Because coursework requires so much work and time, math and physics majors perceived their work as different and harder than other majors. Darcy explained, "A lot of time you can run into the wee hours of the morning because like physics homework is really really different from any other major." She described how her roommate would get frustrated because of the amount of time she spent on homework, perceiving that Darcy was procrastinating. Her roommate's frustration prompted Darcy to explain that her math and physics coursework was difficult not only because the problems required more time to complete, but also because the relationship between time spent on an assignment and final grade were unrelated in physics. Darcy explained that a problem could take hours to complete; but, if she chose the wrong method to solve the problem, the work completed would be worthless. Like Darcy, participants described the time-consuming nature of math and physics coursework as a reason that their major was more difficult than other majors. The constant workload and pressure to meet deadlines led to anxiety and stress for student participants.

\section{Difficult Exams}

Finally, in addition to difficult and time-consuming coursework, exams were designed by faculty to be difficult because the subject matter was hard, as Karl explained previously. Math and physics exams were usually comprehensive exams, as described in a STEM syllabus, "Each exam is semi-comprehensive. And the final exam is fully comprehensive. This means that tests may contain information from throughout the semester." The comprehensive exams in math and physics were difficult because they often had material not covered in class or the homework, and in some cases, were designed to be so time-consuming that they had to be taken outside regular course hours. These tests are intimidating to students and difficult to complete. For example, physics student, Julie, described her last physics exam:

Um, the last test was pretty rough. Well, you know you've got to be worried when they schedule the test outside of class. So it was for a 2-hour period, and that should give you pause in the first place, you know? It's like, okay this is going to be bad, isn't it? And you prepare as well as you can, but he [the professor] is of the opinion that nobody should ever get a $100 \%$ on a test.

The legend of these difficult tests is conveyed to undergraduate physics majors. Olivia expressed anxiety prior to the beginning of the semester about tests she would encounter in her first semester as an upper level physics student. In her second interview, she confirmed that her fears were justified and that the tests were as hard as she had expected.

Participants described how difficult upper level exams were by their receipt of low grades. Math major Emma explained:

Our second test, so there was a couple grad students in there, and our second test it was, our teacher wrote down the class statistics, and I think everyone walked out of the room saying, "Well, I think I guaranteed a $30 \%$ on that test," and anyway, so we get our ... he writes down the statistics on the board, and it's just like 100\%-1. We're just like "who got that?" ... and it was, uh, 90-99\%0; 80-89\%-0; 70-79, there was like seven people; and the D, uh no, there must have been like five people, and the Ds there was probably like seven people, and then there were like 2 Fs.

Participants found exams to be difficult and receiving failing grades reinforced the difficulty of physics and math.

What is unique about the label of "difficulty" is how often it was repeated by participants using similar language. The difficult nature of the field served to guide faculty as they selected course content and to rationalize difficult and time-consuming coursework. Difficulty was also used to rationalize individualistic and competitive classroom practices, leading to intimidating environments. Physics professor, Myles, explained: 
If everyone got a 4.0 coming out of our department, people would laugh at us and you'd never get into grad school 'cause they know you're just giving away the degrees, essentially. Right? You're not learning anything. By its inherent nature, people find it very difficult when you need to learn. Not all of them, but most of them. The average is gonna be lower, right?

Math and physics must be difficult, faculty stated, because that was the very nature of the field. This was an illustration of how difficulty as a discourse is embedded into the institution of STEM in higher education.

\section{Teaching Methods}

Participants were additionally challenged by the teaching environment in math and physics courses. Undergraduate participants felt like they often left class without a clear understanding of what had been covered. First, participants described lecture as the most common teaching strategy used by math and physics faculty. While lecture was not universally disliked by undergraduate participants, the use of lecture allowed for very little student-instructor interaction. Physics major Michelle described how classes usually looked:

The hardest teacher that we have, he would always start out class by filling one-fourth of the chalkboard right away. Before you even got there, he'd get there like 5 minutes early and start writing. And we'd have a little chitchat right at the beginning, and then we'd all start taking notes, and he'd explain things, and he'd ask questions, and most of the time our pauses were for, "What was that subscript that you wrote on that letter?" .. Usually no one says anything. He goes really fast. Which sometimes just doesn't allow you time to think and keep up with him. And most of his questions will go unanswered just purely because of the fact that we didn't have time to think through what he just did. And he would skip steps regularly. He's been teaching this class for so many years, he knows the answer to an integral when you write that on the board. And there's like 15 steps to it. So he'd skip many steps, and we'd be just lost.

Michelle described a typical physics class as being lecture-based with very few student questions, which we also observed during classroom observations. Questions, when asked by faculty, were typically yes/ no questions that received little or no response from students. Undergraduate participants explained that the use of lecture without student interaction required them to teach themselves, something they preferred not to do because they expressed a need to be taught because the material was so hard. Feeling like they had to teach themselves because they were not learning in class caused anxiety for students.

\section{Grading and Assessment}

In addition to difficult coursework, participants described an anxiety caused by grading and assessment practices. Their anxiety was caused by uncertainty about how their grade would be calculated, delayed or unclear feedback, and complicated grading processes.

"I Have No Idea How My Grade is Calculated." First, in both math and physics, students expressed uncertainty about how their final grade would be calculated. In some cases, this uncertainty was because faculty members did not have a grading scale published for students to review in the syllabus, on the Learning Management System (Blackboard), or through in-class descriptions. Darcy explained her interaction with one of her physics professors about how grades would be determined, "He doesn't know yet. I asked him that like a while ago. I was guessing he just hadn't uploaded that to Blackboard, so I was like, 'What's the grading?' And he's like, 'I need to figure that out!' Similarly, Olivia described the expectations in an upper level physics course:

We have tests. He didn't say how many tests. . . he doesn't have one [syllabus]. He just told us like, tests and homework. People have said that he doesn't actually grade things, or he doesn't actually keep your grades. They said like they never got their homework back, and essentially he just kind of picks how he thinks you're doing, and you get your grade based on that.

Lack of clarity about how grades were calculated led Olivia and other undergraduate participants to assume that the grading process was subjective. This assumption increased the pressure on them to perform 
because participants did not know how faculty wanted them to perform. In addition to not understanding their current grade, feedback from professors on assignments and tests was often delayed by weeks or even months. Grades were important to participants because they were an indicator of comprehension and sometimes influenced whether or not a student would receive continued scholarship funding and post-graduation work. As a result, not knowing where they stood as indicated by their grade increased stress and anxiety for each participant in this study.

Difference Between the Math and Physics Environment. While low grades were the norm for math and physics participants, grading practices in math and physics were different because math courses were less likely to grade on a curve. Darcy explained:

Math is way more standardized. Like, if you get like, if you're doing well, you get a 90, where physics is a lot more like, they just really want to challenge you, so like they'll curve it, you know like they'll give a really hard test, and people get really bad grades, and then, you can curve it from there.

While physics was more likely to curve a grade, math was more likely to maintain the standard grading scale where 90 and above was an A and 50 and below was an F. While this adherence to the standardized math scale meant that math majors had a clearer understanding of the expectations regarding their grade, this also created additional pressure on participants to perform to a certain level. Additionally, participants reported that physics professors would tell students to expect low grades, setting an expectation for them that they would receive low grades. Where physics was more likely to make accommodations for a test that everyone failed; in math, that failing grade often directly reflected itself in a student's final grade even if the entire class failed the test. As a result, math participants often viewed low grades on a math exam as failure to understand the concepts presented in class. Physics students did not make that connection as frequently. This created challenges for math participants because while physics students reported understanding that low grades were expected and that their course grades would be curved to help their final course grades, math students perceived failing grades to be evidence they did not understand the content material and would fail the course. As a result, the very real feeling of failure further reduced the comfort level that math student participants felt with their ability to be successful in math.

\section{Intimidating Environments}

Intimidating environments created additional challenges for undergraduate participants. Participants perceived some interactions with faculty and fellow students to contribute to an intimidating environment.

Faculty. First, undergraduate participants described how they felt intimidated by faculty during class and from feedback received on assignments. For example, Olivia described her fear of interacting with one of her physics professors:

He's very intimidating. We'll go to class, and we'll just like spend the whole time [thinking] please don't call on me or ask me something I don't know. 'Cause he's very mean to kids if they get it wrong, or they don't know it. Or, he'll always call on you if you do something wrong. Suddenly, he'll just call on you every time, no matter what. He gets very angry if you don't do something right. He'll put skull and crossbones on your homework if you do something wrong.

Fear of being called on in class and getting the answer wrong had Olivia so stressed that she spent extra time trying to anticipate what the professor might ask in class so that she could answer correctly. By her third interview, Olivia was less intimidated by the professor because she was doing well in the course, but still feared being called on in class.

Other professors were intimidating in a less aggressive way. Michelle explained how another physics professor would intimidate her during class lecture: 
He will sit on a desk right next to you, and ask you, directly, a question. You're in an entirely big class, and he'll sit next to you, and be like what do you think? And he'll like, sit there, and you will have to say the answer ... So you're sitting there; and he's like, eye contact, like staring you down, like all your peers are next to you, and you're like, if I answer this wrong, I'm going to look stupid.

While not every class or professor was described as intimidating, the few that were created a challenge for undergraduate participants. Participants reported dreading their interactions with those faculty members and feared what would happen if they gave incorrect answers in class.

Fellow Students. In addition to intimidating professors, interactions with other physics and math majors can be intimidating as well. Michelle, a physics major, explained: "Like, if there's a new physics major that comes in, and we don't think that they're going to make it, we more often than not, we'll not really be close with them." New students, male and female, are judged by their peers. If they are perceived to not be smart enough, they are made to feel unwelcome. This sentiment also explained why participants were so worried about appearing stupid to their peers.

The unwelcome and intimidating environment was exacerbated by cissexist comments made by a few male students. Samantha described one time she felt unwelcome in her math class:

I mean there's one dude there that has said some pretty sexist and racist things. I forget the joke he made, but I do know that once he made it, he looked at me and went, sorry. It was a joke about women being on their periods or something like that ... And I guess we were on the topic of celebrities while we were on the way walking to calc. It was him and some other dude, and I think he said the words "Bruce Jenner." And then his friend was, "Don't you mean Caitlin Jenner?" And he's like no, no I don't ...

Samantha felt that she could not disclose aspects of her identity as a woman to her male classmates because they might make similar comments about her. She felt like she needed to become inured to sexual language or comments that were derogatory to women in order to be successful in the male-dominated STEM environment.

Individualism. Like difficult coursework, the classroom environment in math and physics was characterized by individualism, as seen in instructional documents and interviews with faculty. First, the emphasis on the individual was seen in course documents, such as the syllabus. For example, a physics syllabus read, "Others may guide you in the acquisition of knowledge and skill, but in the end you teach yourself as a privilege and a responsibility." The onus was placed on the individual for learning and, while group work is not prohibited, this language made it clear that the individual was solely accountable for learning. This focus on the individual in instructional documents was intentional, as Karl explained, "I want them to see a really difficult problem, and I want them to try that without anybody's help. Alone. That is a good feeling because that's everything that I feel. There's a difficult problem. And, I deal with it." Individualism was promoted in the math and physics classroom through an emphasis on the responsibility of learning on the individual.

Competitiveness. Similar to individualism, the competitive nature of math and physics syllabi was seen in instructional documents and expressed by faculty in interviews. First, the competitive environment was exemplified by grading methods. For example, in upper level physics and some math courses, a majority of the grading was based on a curve. Grading on a curve was used to create a competitive environment because competition was seen as a component of the physics professional environment. Likewise, the competitive environment was described on a physics syllabus:

We give grades for a variety of reasons, two of which are:

It allows you to judge your performance on national and international scales;

It is a motivational tool that "encourages" you to further develop your potential. 
Physics and math courses were designed to be competitive as an evaluative and motivational tool.

Faculty used competitive grading methods to help students understand that they would be measured against their peers, which undergraduate participants had internalized. Darcy explained why competition through grading on a curve was necessary, "If you've made it to quantum mechanics, you are good at physics, you're good at math, you're a smart person, so if it wasn't made extra hard, which I think quantum was already inherently hard, then everyone would be getting the same grade." The importance of being able to compare themselves to their fellow students, both within MRU and nationally, was used as a rationale by faculty and students for difficult exams and for grading on a curve. Participants viewed competitive grading and classroom practices as necessary because students would be measured against their peers; and this would determine who received the best scholarships, who would be selected for competitive undergraduate research opportunities, and who would be accepted into graduate school.

\section{Discussion}

Much of the research on the chilly climate has focused on the impersonal nature of the STEM classroom environment and its relationship to the chilly climate and leaky pipeline (Morganson et al., 2010; Vogt et al., 2007), and those practices persisted for participants in this study. While these findings reconfirm prior research (Sidlauskiene \& Butasova, 2013; Sinnes \& Loken, 2014), they also serve as an alert that despite the implementation of interventions to improve the persistence of women in STEM in higher education, the chilly climate continues to persist. We extend prior research by suggesting that the chilly climate persists because the discourses that inform and guide teaching and learning practices and create a chilly climate are institutionalized within STEM education. As a result, because the discourses that inform a chilly class have not changed, the chilly climate persists for undergraduate women (Carnes et al., 2012; Linley \& George-Jackson, 2013; Morimoto, Zajicek, Hunt, \& Lisnic, 2013; Sidlauskiene \& Butasova, 2013). The chilly climate for undergraduate women will persist until the institutionalized masculine discourses of individualism, difficulty, and competition are challenged and changed.

\section{Discourse of Difficulty}

First, similar to prior research on the impact of teaching and learning practices such as those seen in weed-out courses (Gasiewski et al.; Mervis, 2011), the discourse of difficulty created coursework expectations for participants that defined the nature of math and physics learning as exceptionally difficult. Difficult courses, especially when taken as an introduction to math or physics study, act like gatekeepers for students who are intimidated by the difficult, confusing, and time-consuming work (Gasiewski et al., 2012; Mervis, 2011). In this study, the discourse of difficulty was used to rationalize an array of classroom practices that contributed to the chilly climate including time-consuming homework and exams that were so difficult they had to be taken outside of normal class hours, with everyone in the course receiving a failing exam grade. These practices uniquely challenged high-achieving undergraduate women because it made them feel like they could not maintain personal standards of achievement, especially those standards measured by receiving high grades. These findings reinforce research that found that high grades are related to persistence in STEM for undergraduate women (Vogt et al., 2007). Similar to participants in this study, difficult work caused selfdoubt, which led to higher levels of attrition for women (Mervis, 2011; Vogt et al., 2007). Identifying difficulty as the discourse that informed and often motivated teaching and learning practices in the STEM classroom contributes understanding to why those practices persist.

\section{Individualism}

Second, the masculine discourse of individualism guided an institutional environment where the responsibility for learning was placed on the individual, reinforcing prior research on the individualistic nature of STEM education (Morganson, Jones, \& Major, 2010; Vogt, Hocevar, \& Hagedorn, 2007). The discourse of 
individualism informed a teaching and learning environment that focused on individual success, "the view that people succeed because of superior abilities, dedication, and performance" (Acker, 2000, p. 630). The emphasis on individualism created anxiety for participants who felt that they did not have the knowledge to teach themselves. However, participants were reluctant to go to faculty for help (e.g., asking questions in and outside of class) because they feared that this would reinforce a perception that women could not be successful in math and physics. Lack of support created the bind described by Morganson et al., (2010) where women in STEM struggled because the coping strategies they were accustomed to were not supported by the college and STEM faculty. As a result, changing practices such as adding new support mechanisms was insufficient to remedy the chilly climate without changing the discourse of individualism. The discourse of individualism informs teaching and learning practices that place the onus on undergraduate women, reducing support (Morganson et al., 2010 Sartorius, 2010), and possibly increasing feelings of incompatibility between themselves and their major (Deemer et al., 2014; Herzig, 2010; Kreutzer \& Boudreaux, 2012; London et al., 2011; Yakaboski, 2011).

\section{Competition}

Third, reinforcing prior research on the competitive STEM classroom environment (Mervis, 2011; Morganson et al., 2010; Shapiro \& Sax, 2011), the masculine discourse of competition was promoted as a necessary part of STEM by faculty and student participants and led to teaching methods, grading practices, and classroom environments that were discomfiting for undergraduate participants. Related to the discourse of individualism, a competitive climate contributes to the leaky pipeline, because women do not find competition a meaningful way to receive feedback (Shapiro \& Sax, 2011). As an accepted pedagogy in STEM education, competitive practices such as grading on a curve have been found to be contrary to women's need for collaboration and a collectivistic environment (Shapiro \& Sax, 2011; Vogt et al., 2007). Reinforcing these findings and prior research (Carrell et al., 2010; Carrigan et al., 2011; Thomas, Bystydzienski, \& Desai, 2014), undergraduate participants in this study described how important the student community was to their success and expressed a dislike of competitive practices, even when they acknowledged they were necessary to differentiate students for undergraduate research and graduate school applications. Faculty sought to preserve the competitive environment by grading on a curve and the larger STEM environment maintained a competitive environment through the processes of applying to graduate school and undergraduate research, the competitive environment persisted. In that way, competitive environments, especially without academic and social support from faculty, contribute to the chilly climate and leaky pipeline.

\section{Conclusion}

As a result of the masculine STEM teaching and learning environment, efforts to reduce the chilly climate have been unsuccessful, largely because the masculine discourses that motivate the chilly climate have not changed. The first step to improve the chilly climate in STEM fields requires revising the STEM institution from one that is masculine to one that is inclusive for non-man students. The goal is to create a STEM education environment that supports, validates, and gives women an equal voice (Sidlauskiene \& Butasova, 2013). It is hoped that these recommendations can help to improve the experiences on women in STEM and, as a result, improve the recruiting and retention of women in STEM.

\section{Recommendations}

Recommendations to move toward a more equitable environment include empowering undergraduate women by giving them decision-making power, such as course enrollment choices, undergraduate research options, and in classroom projects. Similarly, the presence of women faculty can provide examples of a career progression path that demonstrates that women can be successful in STEM (Carrel et al., 2010; Charleston et al., 2014; DuPre, 2010; Gorman et al., 2010; Rosenthal et al., 2011; Tatum et al., 2013). Further, related to increasing the number of women faculty and students, departments need to improve support for undergraduate women from faculty, continuing research-based programs designed to support women until all faculty and staff practice 
the support provided by those programs. Programs that support women students should include social coping development and support (Morganson et al., 2010), promote self-efficacy (Brown, Garavalia, Fritts, \& Olson, 2006), teach bias awareness (Suresh, 2006), and provide academic support (Yelamarthi \& Mawasha, 2010). For example, mentoring has been found to promote the persistence and success of women in science (Borum \& Walker, 2012; Campbell \& Skoog, 2004; Griffin et al., 2010). Successful organized mentoring programs in STEM provide opportunities for women to be involved in undergraduate research and alerting students to the obstacles they were likely to face as women in STEM (Griffin et al., 2010).

\section{Future Research}

Future research must take into account the intersectional identities that influenced the experiences of women in STEM. While intersectionality was not the framework of this study and demographics at MRU do not represent the ethnic diversity of the United States, this study was not able to deeply explore the intersectionality that is particularly important in understanding how minorities are marginalized in STEM education. However, gender was not the only aspect of identity that affected participants' experiences in STEM; for participants, "multiple social identities shape thelives of oppressed individuals" (Museus \& Griffin, 2011, p. 6). Intersectionality "promotes a greater understanding of how converging identities contribute to inequality" (Museus \& Griffin, 2011, p. 10), and attention to intersectionality in future research is key to understanding how other aspects of their identity interacted to create different challenges in the STEM environment. Second, while the research was framed through feminist standpoint theory, beginning from the experiences of undergraduate women, the teaching and learning environment described could be perceived as chilly for all students, regardless of gender. Future research could include additional participant experiences to understand if and how experiences of the climate differ according to gender.

\section{References}

Acker, J. (2000). Gendered contradictions in organizational equity projects. Organization, 7(4), 625-632.

Belenky, M. F., Clinchy, B. M., Goldberger, N.R., \& Tarule, J. M. (1997). Women's Ways of Knowing. New York, NY: Basic Books.

Borum, V., \& Walker, E. (2012). What makes the differences? Black women's undergraduate and graduate experiences in mathematics. Journal of Negro Education, 81(4), 366-378.

Campbell, M. \& Gregor, F. (2004). Mapping Social Relations: A Primer in Doing Institutional Ethnography. Walnut Creek, CA: AltaMira Press.

Campbell, A. \& Skoog, G. (2004). Preparing undergraduate women for science careers. Journal of College Science Teaching, 33(5), 24-26.

Carnes, M., Devine, P. G., Isaac, C., Manwell, L. B., Ford, C. E., Byars-Winston, A., \& Sheridan, J. (2012). Promoting institutional change through bias literacy. Journal of Diversity in Higher Education, 5(2), 63-77. doi:10.1037/a0028128

Carrell, S. E., Page, M. E., \& West, J. E. (2010). Sex and science: How professor gender perpetuates the gender gap. Quarterly Journal of Economics, 125(3), 1101-1144.

Carrigan, C., Quinn, K., \& Riskin, E. A. (2011). The gendered division of labor among STEM faculty and the effects of critical mass. Journal of Diversity in Higher Education, 4(3), 131-146.

Carspecken, F.P. (1996). Critical Ethnography in Educational Research: A Theoretical and Practical Guide [Kindle Reader version]. New York, NY: Routledge. Retrieved from http://www.amazon.com/CriticalEthnography-Educational-Research-Theoretical-ebook/dp/B00FDR4P74/ref=tmm_kin_title_0? encoding=UTF8\&sr=8-1\&qid $=1419264649$ 
Charleston, L. J., George, P. L., Jackson, J. L., Berhanu, J., \& Amechi, M. H. (2014). Navigating underrepresented STEM spaces: Experiences of Black women in U.S. computing science higher education programs who actualize success. Journal of Diversity in Higher Education, 7(3), 166-176. doi:10.1037/a0036632

Creswell, J. W. (2013). Qualitative Inquiry \& Research Design. Thousand Oaks, CA: Sage Publications.

Deemer, E. D., Thoman, D. B., Chase, J. P., \& Smith, J. L. (2014). Feeling the threat: Stereotype Threat as a contextual barrier to women and science career choice intentions. Journal of Career Development, 41(2), 141-158.

DuPre, C. (2010). Does being a good girl lead to being a good student? Teaching English in the Two-year College, 38(1), 68-77.

Gayles, J. G., \& Ampaw, F. (2014). The impact of college experiences on degree completion in STEM fields at four-year institutions: Does gender matter? Journal of Higher Education, 85(4), 439-468.

Gasiewski, J., Eagan, M., Garcia, G., Hurtado, S., \& Chang, M. (2012). From gatekeeping to engagement: A multicontextual, mixed method study of student academic engagement in introductory STEM courses. Research in Higher Education, 53(2), 229-261. doi:10.1007/s11162-011-9247-y

Gorman, S. T., Durmowicz, M. C., Roskes, E. M., \& Slattery, S. P. (2010). Women in the academy: Female leadership in STEM education and the evolution of a mentoring web. Forum on Public Policy Online, $2010(2)$.

Griffin, K. A., Perez, D. I., Holmes, A. E., \& Mayo, C. P. (2010). Investing in the future: The importance of faculty mentoring in the development of students of color in STEM. New Directions for Institutional Research, (148), 95-103.

Harding, S. (2004). A socially relevant philosophy of science? Resources from standpoint theory's controversiality. Hypatia, 19(1), 25-47.

Herzig, A. H. (2010). Women belonging in the social worlds of graduate mathematics. Montana Mathematics Enthusiast, 7(2/3), 177-208.

Hesse-Biber \& Nagy, S. J. (2014). Feminist Research Practice: A Primer. Thousand Oaks, CA: SAGE Publications, Inc.

Linley, J. L., \& George-Jackson, C. E. (2013). Addressing underrepresentation in STEM fields through undergraduate interventions. New Directions for Student Services, 2013(144), 97-102.

London, B., Rosenthal, L., Levy, S.R., and Lobel, M. (2011). The influences of perceived identity compatibility and social support on women in nontraditional fields during the college transition. Basic and Applied Social Psychology, 33, 304-321. doi:10.1080/01973533.2011.614166

Maxwell, J.A. (2013). Qualitative Research Design: An Interactive Approach. Thousand Oaks, CA: Sage Publications, Inc.

Mervis, J. (2011). Weed-out courses hamper diversity. Science, 334(6061), 1333.

Morganson, V. J., Jones, M. P., \& Major, D. A. (2010). Understanding women's underrepresentation in science, technology, engineering, and mathematics: The role of social coping. Career Development Quarterly, 59(2), 169-179.

Morimoto, S.A., Zajicek, A.M., Hunt, V.H., \& Lisnic, R. (2013). Beyond binders full of women: NSF advance and initiatives for institutional transformation. Sociological Spectrum, 33. 397-415.

Museus, S. D., \& Griffin, K. A. (2011). Mapping the margins in higher education: On the promise of intersectionality frameworks in research and discourse. New Directions For Institutional Research, 2011(151), 5-13.

Onwuegbuzie, A. J. \& Leech, N. L. (2007). Validity and qualitative research: An oxymoron? Quality \& Quantity, 41, 233-249. 
Parson, L. (In Press, 2018). An institutional ethnography of higher education: The experiences of undergraduate women majoring in math and physics. Journal of Ethnographic and Qualitative Research.

Parson, L. \& Ozaki, C. C. (2017). Gendered student ideals in STEM in higher education. NASPA Journal about Women in Higher Education. DOI: 10.1080/19407882.2017.1392323

Rosenthal, L., London, B., Levy, S., \& Lobel, M. (2011). The roles of perceived identity compatibility and social support for women in a single-sex STEM program at a co-educational university. Sex Roles, 65(9/10), 725-736. doi:10.1007/s11199-011-9945-0

Saldana, J. (2013). The Coding Manual for Qualitative Researchers. Thousand Oaks, CA: Sage Publications Inc.

Sartorius, K. C. (2010). Experimental autonomy: Dean Emily Taylor and the women's movement at the University of Kansas. Kansas History: A Journal of the Central Plains, 33, 2-21.

Shapiro, C. A., \& Sax, L. J. (2011). Major Selection and Persistence for Women in STEM. New Directions for Institutional Research, (152), 5-18.

Šidlauskienè, V., \& Butašova, K. (2013). Designing gender equality as institutional transformation at a higher education institution. Gender Studies \& Research, 11, 50-69.

Sinnes, A. T., \& Løken, M. (2014). Gendered education in a gendered world: looking beyond cosmetic solutions to the gender gap in science. Cultural Studies of Science Education, 9(2), 343-364.

Smith, D. E. (2005). Institutional Ethnography: A Sociology for People. Lanham, MD: Altamira Press.

Smith, D. E. (2006). Institutional Ethnography as Practice. Lanham, MD: Rowman \& Littlefield Publishers, Inc.

Tatum, H. E., Schwartz, B. M., Schimmoeller, P. A., \& Perry, N. (2013). Classroom participation and studentfaculty interactions: Does gender matter? Journal of Higher Education, 84(6), 745-768.

Thomas, N., Bystydzienski, J., \& Desai, A. (2014). Changing institutional culture through peer mentoring of women STEM faculty. Innovative Higher Education, (Preprints), 1-15.

Vogt, C. M., Hocevar, D., \& Hagedorn, L. (2007). A social cognitive construct validation: Determining women's and men's success in engineering programs. Journal of Higher Education, 78(3), 337-364.

Yakaboski, T. (2011). "Quietly stripping the pastels:" The undergraduate gender gap. Review of Higher Education, $34(4), 555-580$. 